\title{
Influence of age and previous diet of Anopheles gambiae on the infectivity of natural Plasmodium falciparum gametocytes from human volunteers
}

\author{
Bernard A. Okech ${ }^{\mathrm{a}, \mathrm{b}, \mathrm{c}}$, Louis C. Gouagna ${ }^{\mathrm{b}}$, Ephantus W. Kabiru $^{\mathrm{c}}$, John C. Beier ${ }^{\mathrm{e}}$, Guiyun Yan ${ }^{\mathrm{d}}$, John I. Githure ${ }^{\mathrm{b}}$ \\ ${ }^{a}$ Kenya Medical Research Institute, P. O. Box 54840, Nairobi, Kenya \\ ${ }^{b}$ International Centre of Insect Physiology and Ecology (ICIPE), P. O. Box 30772, Nairobi, Kenya \\ ${ }^{c}$ Department of Zoology, Kenyatta University, P. O. Box 43844, Nairobi, Kenya \\ ${ }^{d}$ Department of Biological Sciences, State University of New York, Buffalo, NY, 14260, USA \\ ${ }^{e}$ Department of Epidemiology and Public Health, University of Miami School of Medicine, Miami, FL 33136, USA \\ bokech@nairobi.mimcom.net
}

Received 03 February 2003, Accepted 17 July 2004, Published 22 October 2004

\begin{abstract}
The effect of age and dietary factors of Anopheles gambiae (Diptera: Culicidae) on the infectivity of natural Plasmodium falciparum parasites was studied. Mosquitoes of various ages (1-3, 4-7 and 8-11 day old) and those fed blood (either single or double meals) and sugar meals were experimentally co-infected with $P$. falciparum gametocytes obtained from different naturally infected human volunteers. On day 7, midguts were examined for oocyst infection to determine whether mosquito age or diets have significant effects on parasite infectivity. The age of the mosquitoes did not significantly influence the oocyst infection rates $\left(\chi^{2}=48.32, \mathrm{df}=40, \mathrm{P}=0.172\right)$ or oocyst load (\# of oocysts/midgut) $(\mathrm{P}=0.14)$ observed. Oocyst load between groups was not significantly different. Similarly, the type of diet (either blood or sugar) did not influence oocyst infection rates $\left(\chi^{2}=16.52\right.$, df $=19, \mathrm{P}=0.622$ ). However, an increase in oocyst infection rates resulted after previous feeding on double blood meals (35\%) compared to single blood meals (25\%), with comparable oocyst load. These observations are in agreement with those reported in previous studies suggesting that increased mosquito nutritional reserves resulting from increased dietary resources is favorable for malaria infectivity. This field-based study indicates that vector competence of An. gambiae to natural P. falciparum parasites does not vary with age and that nutritional resources acquired prior to an infectious blood meal plays a crucial role in mosquito-parasite relationships.
\end{abstract}

Keywords: An. gambiae, blood and sugar feeding, malaria infectivty, mosquito age, oocysts, $P$. falciparum, sporogony

\section{Abbreviation:}

oocyst load

oocyst infection rates

number of oocysts per midgut

percent of midguts with oocysts

\section{Introduction}

The African malaria vectors especially species of the Anopheles gambiae complex exhibit unique feeding behaviors that often influences greatly their lifespan and fecundity. The adult mosquitoes feed on sugars from plant nectar, which provide for immediate energy demands (Clements 1992, Foster 1995). Although An. gambiae can survive on plant nectar, the females require a blood meal for egg development, which also provides an alternative energy source for survival (Nayar and Sauerman 1975), especially during the dry season when nectar sources are often scarce. In their search for blood meals, An. gambiae mosquitoes will most probably get into contact with human hosts, many of whom may carry gametocytes, particularly in malaria endemic areas. However, whether previous sugar feeding influences malaria infectivity and transmission in nature is still unknown. Although studies have shown

that the previous feeding on sugar meals enhances the infection rates in mosquitoes (Kelly and Edman 1997), the shortcoming of such studies is the use of cultured strains of parasites that are not representative of wild type parasites that exist in nature. No studies have been done to examine the effect of sugar meals on the infectivity of $P$. falciparum parasites from naturally infected gametocyte carriers to mosquitoes.

An. gambiae, the major malaria vector in Africa, exhibits a behavioral trait in which the mosquito takes many blood meals in a single egg laying cycle (Briegel and Horler 1993). This behavior, termed gonotrophic discordance, helps the mosquito fully mature its eggs (Briegel and Horler 1993), and also enhances survivorship in the absence of sugar meals (Straif and Beier 1996). Examination of the direct effect of multiple-blood feeding behavior on the malaria parasite as it develops within the vector is critical in order to understand its importance on the overall transmission process. 
Okech BA, Gouagna LC, Kabiru EW, Beier JC, Yan G., and Githure JI. 2004. Influence of age and previous diet of Anopheles gambiae on the infectivity of natural Plasmodium falciparum gametocytes from human volunteers. 8pp. Journal of Insect Science, 4:33, Available online: insectscience.org/4.33

Laboratory-based studies have shown that several previous blood meals reduce the chance of successful malaria development in Anopheles mosquitoes (Vaughan et al. 1994). The frequency of blood feeding in An. gambiae not only increases in the absence of sugar (Beier 1996) but also with age (Straif and Beier 1996). Both aspects of the mosquito life history (exposure to multiple diets and age) may have consequences for malaria parasite infectivity. Here we used $P$. falciparum gametocyte-positive blood obtained from infected human volunteers in western Kenya to determine whether mosquito age and previous diet have an influence on malaria parasite infectivity within experimentally infected An. gambiae mosquitoes.

\section{Materials and Methods}

\section{Study area}

The study was conducted in Mbita Division, Suba District, south-western Kenya at the ICIPE-Mbita Point Field Station; the area has been described extensively elsewhere (Gouagna et al. 2003). The area has stable, endemic malaria (Mutero et al. 1998) where An. gambiae, An. arabiensis Patton and An. funestus Giles all contribute to perennial malaria transmission (Shililu et al. 2004).

\section{Mosquitoes used in the experiments}

A local strain of An. gambiae s.s mosquito adapted for artificial parafilm membrane feeding was used for all experiments. The mosquitoes were reared in trays containing about 200 larvae per $20 \times 15 \mathrm{~cm}$ tray and fed on a 10\% slurry of parts 2:1 Tetramin Baby $\mathrm{E}^{\circledR}$ fish food to Bakers yeast. The rearing environment was confined within a semi-field, mesh-walled greenhouse house environment exposed to ambient airflow and climatic conditions. Pupae were collected and kept in $30 \mathrm{~cm} \times 30 \mathrm{~cm} \times 30 \mathrm{~cm}$ meshcovered cages where emerging adults were kept and manipulated for the intended experiments.

\section{Aging experiments}

Three batches of mosquitoes were collected shortly after emergence and provided with a daily access to $10 \%$ glucose solution in cotton wicks that were changed every day, until they reached the desired ages of 1-3 days, 4-7 days and 8-11 days, when they were used for experiments. For each experiment, 100 female mosquitoes were randomly aspirated and assigned to 3 holding cups, thereby avoiding a size bias that might have affected the infection outcome (Lyimo and Koella 1992).

\section{Nutritional history experiments}

Batches of emerging mosquitoes were randomly selected and kept trapped in 3 cages and provided with different diet regimens. The first group received one blood meal every 4 days for 8 days so that overall it received 2 blood meals. The second group received one blood meal in 8 days, and the third group received only sugar meals for 8 days. Thus, the first group received 2 previous blood meals, second group 1 previous blood meal and third group no previous blood meal. All three groups of mosquitoes were of the same age (8-11days old) at the time of use. In the first set of experiments, 3 groups of 100 female mosquitoes from each of the
3 cages were co-infected with P. falciparum gametocytes from 29 infected human volunteers, each experiment conducted separately with a different gametocyte carrier. In the second set of experiments, two cages of emerging mosquitoes were set aside with one cage receiving $10 \%$ glucose solution immediately on emergence and the other cage receiving distilled water. On day 2, 100 mosquitoes were aspirated and randomly put into each of 2 experimental cups. They were simultaneously fed an infectious blood meal containing $P$. falciparum gametocytes from human volunteers. The experiment was repeated with at least 20 different gametocyte positive volunteers.

\section{Selection of $\mathrm{P}$. falciparum gametocyte carriers}

The Ethical Review Boards of the Kenya Medical Research Institute in Kenya and Tulane University in the USA approved the procedure used for selection of volunteers. The protocol provided that gametocyte carriers between the ages 3-45 years could be recruited on a voluntary basis (Gouagna et al. 2003). The inclusion criteria included presence of single species of $P$. falciparum, gametocyte density of above 16 gametocytes per $\mu \mathrm{l}$ of blood, and signed informed consent. Exclusion criteria included the presence of other concomitant diseases requiring hospitalization or follow up, severe clinical symptoms, pregnant women and refusal to sign informed consent forms. Volunteers were recruited from the local clinic (Mbita Health Centre) during patient consultation every week, and from daily cross sectional surveys done at schools and the village communities surrounding the ICIPE - Mbita Point Research Station (Gouagna et al. 2004). Uncomplicated malaria cases and asymptomatic subjects with slide-confirmed malaria at intensities greater than 1000 parasites per microlitre of blood were treated with sulfadoxine-pyrimethamine (Fansidar ${ }^{\circledR}$ ). P. falciparum gametocyte carriers observed with densities greater than 16 per $\mu \mathrm{l}$ of blood were selected and asked to participate in the study.

\section{Mosquitoes infection and dissection for oocysts}

Mosquitoes for infection experiments were starved for 68 hours prior to feeding on infectious blood. During experimental infections, the clinician withdrew $3 \mathrm{ml}$ of venous blood into heparinized tubes from each volunteer. This blood sample was immediately fed to mosquitoes using artificial membrane mini-feeders prewarmed to $37^{\circ} \mathrm{C}$ as previously described (Tchuinkam et al. 1993). Mosquitoes were allowed to feed for 15 minutes after which they were sorted out and the unfed mosquitoes discarded while the fed mosquitoes were maintained on $10 \%$ glucose solution. All mosquitoes were transferred into a $27^{\circ} \mathrm{C}$ incubator and maintained on a $10 \%$ glucose solution that was changed every day until they were dissected on day 7-post infection. Upon dissection, their midguts were individually stained with $2 \%$ mercurochrome and examined under a light microscope at $\times 10$ objective lens for the presence of oocysts. At the same time, the left wing was removed and measured using an ocular micrometer as an index of body size (Takken et al. 1998).

\section{Statistical analysis}

Descriptive statistics were applied to compute the oocyst infection rates in groups (defined as the proportion of mosquitoes positive with oocysts from the total number of mosquitoes dissected), 
Okech BA, Gouagna LC, Kabiru EW, Beier JC, Yan G., and Githure JI. 2004. Influence of age and previous diet of Anopheles gambiae on the infectivity of natural Plasmodium falciparum gametocytes from human volunteers. 8pp. Journal of Insect Science, 4:33, Available online: insectscience.org/4.33

and the mean oocyst load (defined as the average of oocyst counts in all the positive mosquito midguts expressed as oocysts/mid gut). Both of these indicators have been used to monitor mosquito infections in different experimental groups. Because of the differences in infectiousness among the gametocyte carriers (Muirhead-Thomson 1954; Githeko et al. 1992), the analysis was conducted by individual carrier. Prior to analysis, the mean oocyst intensities were transformed (natural logarithm) to normalize their distribution. The differences in mean oocyst intensity between experimental groups was computed using ANOVA procedure while the association between oocyst infection rates and mosquito characteristics (including age, and diet regimen) was analyzed using Pearson's Chi square in the SPSS software version 11 for windows. The independent sample T-test (2-tailed) was used to analyze the differences in mean oocyst intensity between the experimental groups (sugar/no sugar), assuming equality of variances since the groups of mosquitoes were co-infected from same human volunteers. Mosquitoes were randomly assigned to groups so that differences in mosquito size were random between them. Wing measurements were used to assess differences in mosquito size.

\section{Results}

\section{Effect of mosquito age}

Fourteen gametocyte carriers were recruited for this set of experiments and a total of 14 replicates were conducted with the different gametocyte carriers. A higher proportion of gametocyte carriers (=infection experiments) produced oocysts in the 4-7 day old mosquitoes (11/14) than in the 1-3 day old (8/13) or 8-11day old (6/13) (Table 1). Although no association between oocyst infection rates and age classes of mosquitoes was detected $\left(\chi^{2}=\right.$ 48.32, $\mathrm{df}=40, \mathrm{P}=0.172)$, the oocyst infection rates appeared to be higher in the 4-7day old mosquitoes (Table 1). Fewer mosquitoes were dissected on day 7 in the 8-11 age class, probably due to age related mortality. However, this did not select for larger sized mosquitoes (which are likely to live longer) in this group as there were no significant differences in the mean wing sizes of the mosquitoes across the age groups (ANOVA: $\mathrm{df}=2, \mathrm{~F}=2.00, \mathrm{P}=$ 1.151) (Table 2). The wing sizes were $2.92 \pm 0.14$ for the $1-3 \mathrm{~d}$, $2.98 \pm 0.21$ for the $4-7 \mathrm{~d}$, and $2.98 \pm 0.14$ for the $8-11$ day old mosquitoes. The oocyst load in the midguts of infected mosquitoes was also not significantly different between age groups (ANOVA: $\mathrm{df}=2, \mathrm{~F}=2.14, \mathrm{P}=0.14$ ).

\section{Effect of previous diet}

Twenty-nine replicates of experiments were conducted with different volunteers (mean age $8.7 \pm 3.9$; range 3-25). There was a similar proportion of gametocyte carriers yielding oocyst infections in the 3 mosquito groups (No blood meal, 1 blood meal, 2 blood meals) used in this study (Table 2). Neither the number of previous blood meals $\left(\chi^{2}=33.09, \mathrm{df}=38, \mathrm{P}=0.696\right)$ nor the type of diet (sugar or blood meals) $\left(\chi^{2}=16.52, \mathrm{df}=19, \mathrm{P}=0.622\right.$ ) influenced oocyst infection rates in mosquitoes. Similarly the between-group differences in oocyst intensity were not significant (ANOVA: $\mathrm{df}=2, \mathrm{~F}=0.511, \mathrm{P}=0.607$ ). The mean wing sizes between experimental groups (Table 2) were not significantly different (ANOVA: $d f=2, F=1.14, P=0.333$ ). A higher oocyst infection rate was observed in the group of mosquitoes fed 2 previous blood meals (Table 3 ). When the data were grouped by sugar alone or blood meal ( 1 or 2$)$, there was still no significant difference in

Table 1. The oocyst infection rates and oocyst load in mosquito groups of various age categories. Data shown are per individual gametocyte carrier used in the infection experiments.

\begin{tabular}{|c|c|c|c|c|c|c|c|c|}
\hline \multicolumn{2}{|c|}{ Gametocyte } & \multirow[b]{2}{*}{ Macros $\dagger$} & \multicolumn{3}{|c|}{ Oocyst infection rate } & \multicolumn{3}{|c|}{ Oocyst load } \\
\hline Carrier & density & & 1-3days & 4-7days & 8-11days & 1-3days & 4-7days & 8-11days \\
\hline 1 & 16 & 15 & $7.1(5 / 70)$ & $10.0(1 / 10)$ & $0.0(0 / 9)$ & 1.4 & 1 & 0 \\
\hline 2 & 32 & 31 & $2.5(1 / 40)$ & $7.7(2 / 26)$ & $0.0(0 / 6)$ & 1 & 1 & 0 \\
\hline 3 & 16 & 15 & $0.0(0 / 21)$ & $0.0(0 / 8)$ & $6.3(1 / 16)$ & 0 & 0 & 1 \\
\hline 4 & 96 & 95 & $5.0(1 / 20)$ & $5.3(1 / 19)$ & $0.0(0 / 9)$ & 1 & 1 & 0 \\
\hline 5 & 64 & 63 & $9.3(4 / 43)$ & $8.3(2 / 24)$ & $6.3(1 / 16)$ & 2.5 & 1 & 4 \\
\hline 6 & 80 & 79 & $0.0(0 / 44)$ & $9.7(3 / 31)$ & $11.1(1 / 9)$ & 0 & 1 & 1 \\
\hline 7 & 48 & 47 & $3.1(2 / 64)$ & $0.0(0 / 17)$ & $12.5(1 / 8)$ & 1.5 & 0 & 2 \\
\hline 8 & 16 & 15 & $0.0(0 / 19)$ & $0.0(0 / 7)$ & $0.0(0 / 33)$ & 0 & 0 & 0 \\
\hline 9 & 16 & 15 & $0.0(0 / 24)$ & $6.7(1 / 15)$ & $0.0(0 / 7)$ & 0 & 1 & 0 \\
\hline 10 & 16 & 15 & $8.7(6 / 69)$ & $3.6(1 / 28)$ & $0.0(0 / 24)$ & 1.3 & 1 & 0 \\
\hline 11 & 32 & 31 & $2.9(1 / 34)$ & $6.7(3 / 45)$ & $12.5(1 / 8)$ & 1 & 1 & 1 \\
\hline 12 & 16 & 15 & $0.0(0 / 13)$ & $6.7(1 / 15)$ & $0.0(0 / 1)$ & 0 & 1 & 0 \\
\hline 13 & 16 & 15 & $3.9(1 / 26)$ & $66.7(2 / 3)$ & $7.1(1 / 14)$ & 1 & 1 & 1 \\
\hline 14 & 16 & 15 & ND & $11.8(2 / 17)$ & ND & ND & 1 & ND \\
\hline & 35.2 & & ${ }^{*} 4.7(20 / 429)$ & ${ }^{*} 6.4(14 / 223)$ & ${ }^{*} 4.5(5 / 112)$ & ${ }^{\top} 1.4 \pm 0.2$ & ${ }^{\natural} 1.0 \pm 0.0$ & ${ }^{\top} 1.8 \pm 0.6$ \\
\hline
\end{tabular}

$\dagger$ The macrogametocyte (=macros) density ingested by the mosquitoes was estimated by multiplying the mean blood meal volume of membrane fed mosquitoes by the mean number of macrogametocytes per $\mathrm{ml}$ of blood as described by Okech et al. (2004). *Represents the overall oocyst infection rates computed by the total number of positive mosquitoes divided by the total number of mosquitoes dissected.

ND - Not done.

ITThe average of the mean number of oocysts on the infected mosquito midguts \pm standard error of the mean (SEM). 
Okech BA, Gouagna LC, Kabiru EW, Beier JC, Yan G., and Githure JI. 2004. Influence of age and previous diet of Anopheles gambiae on the infectivity of natural Plasmodium falciparum gametocytes from human volunteers. 8pp. Journal of Insect Science, 4:33, Available online: insectscience.org/4.33

oocyst load $(\mathrm{P}=0.708)$ between sugar fed or blood fed mosquitoes, although the oocyst infection rate in blood fed mosquitoes $(8.8 \%)$ tended to be higher than in the sugar fed mosquitoes (5.4\%). When single and double blood fed mosquitoes were compared, the percent oocyst infection rate observed in mosquitoes provided two blood meals $(11.6 \%)$ was higher than in mosquitoes provided single blood meal $(5.7 \%)$ even though the oocyst load between them was not significantly different $(\mathrm{T}=-0.614, \mathrm{df}=15, \mathrm{P}=0.549)$.

\section{Effect of previous sugar feeding}

Thirty five percent of the gametocyte carriers (7/20) produced oocyst infections in mosquitoes provided with distilled water (no sugar) compared to $25 \%(5 / 20)$ in the sugar group (Table 4). However, whether mosquitoes were provided sugar or not did not influence the oocyst infection rates observed $\left(\chi^{2}=10.14\right.$, $\mathrm{df}=$ $11, \mathrm{P}=0.518)$. The prevalence of oocyst infection was marginally higher in mosquitoes provided no sugar $(2.9 \%)$ compared to the sugar fed mosquitoes (2.2\%) even though the mean oocyst intensity between the 2 experimental groups was not statistically different $(\mathrm{T}=-1.097, \mathrm{df}=10, \mathrm{P}=0.298)$. The mosquito sizes, based on the wing measurements of the 2 groups of mosquitoes were not statistically different $(\mathrm{P}=0.985)$.

\section{Discussion}

This study has shown that age of the mosquito does not influence malaria infectivity in An. gambiae as all mosquito age categories were equally likely to develop oocysts in their midguts. The results of the study also show that the type of diet given to mosquitoes may increase the infection rates with $P$. falciparum oocysts. In particular, mosquitoes that previously fed on blood, either as single or multiple previous blood meals resulted in a larger proportion of these mosquitoes developing oocysts. Interestingly, for very young mosquitoes less than two days old, provision of sugar prior to the infectious blood meal, resulted in a marginal drop in proportion of infected mosquitoes as compared to non sugar fed mosquitoes, and did not result in significant increases in oocyst load.

This study demonstrates that regardless of age, mosquitoes were likely to have similar oocyst infection prevalence and oocyst loads. Under natural conditions, it is unknown whether competency for malaria transmission would change with mosquito age. Hypothetically, the age at the time a mosquito encounters a parasite may be influential because only mosquitoes that survive for the duration of time equal or greater than the sporogonic development are important vectors epidemiologically (Okech et al. 2003). This study shows that the overall effect of age on infectivity seems negligible. But there are reports indicating that exposure to parasites may lead to reduced vector fitness and survival (Ferguson and Read 2002). Anecdotal evidence based on parity and salivary gland dissections have suggested this possibility but to date there was no experimental evidence to demonstrate it. Here we have shown that age of the mosquitoes will not influence the outcome of the infection. However, the impact of mosquito age on malaria transmission may occur as a result of age related mortality (Okech et al. 2003), which was very evident in our experiments, as fewer numbers of mosquitoes survived to day 7 for dissections in the older age groups than in younger age groups. Age related population declines of infective mosquitoes in nature may be amplified by parasite infection (Ferguson and Reid 2002). Whereas older mosquitoes may have had an opportunity to acquire more nutrients and hence more accumulated nutritional reserves (see next paragraph), our data did not find any major variation in oocyst infection rates or intensity as compared to the other groups. These results demonstrate that parasite development inside the mosquito does not depend on the age of the vector at the time it encounters parasites.

Nutrient acquisition by adult mosquitoes may increase the oocyst infection rates in mosquitoes as our study demonstrated. The need to acquire blood meals is driven by the survival and

Table 2. The wing sizes of mosquitoes dissected in infection experiments on day 7 . The wing measurements are given in millimeters \pm standard deviation.

\begin{tabular}{|cccc|}
\hline Experimental infections & $\mathrm{N}$ & Wing size $(\mathrm{mm})$ & P value \\
\hline Aging infections: & & & \\
$1-3$ days old & 233 & $2.92 \pm 0.14$ & \\
$4-7$ days old & 118 & $2.98 \pm 0.21$ & 0.151 \\
$8-11$ days old & 71 & $2.98 \pm 0.14$ & \\
\hline Previous blood feeding: & & & \\
No blood meal & 154 & $2.95 \pm 0.31$ & \\
1 blood meal & 177 & $2.86 \pm 0.33$ & 0.333 \\
2 blood meal & 212 & $2.90 \pm 0.31$ & \\
\hline Sugar feeding: & & & \\
No sugar & 559 & $2.67 \pm 0.305$ & 0.985 \\
10\% glucose & 541 & $2.67 \pm 0.305$ & \\
\hline
\end{tabular}

$\mathrm{N}-$ Total number of mosquitoes dissected. 
Okech BA, Gouagna LC, Kabiru EW, Beier JC, Yan G., and Githure JI. 2004. Influence of age and previous diet of Anopheles gambiae on the infectivity of natural Plasmodium falciparum gametocytes from human volunteers. 8pp. Journal of Insect Science, 4:33, Available online: insectscience.org/4.33

reproductive instincts in the mosquito because blood meals offer more, in terms of energy reserves and reproductive fitness than sugar meals for the mosquito (Gary and Foster 2001). In this study, mosquitoes that were previously fed two blood meals exhibited a tendency to having a higher oocyst infection rate than mosquitoes feeding on a single blood meal or none at all. Blood feeding increases enzyme secretions, which can be deleterious to midgut parasites (Gass 1977), however such enzyme activity peaks at $36 \mathrm{hrs}$ (Billingsley and Hecker 1991, Chadee and Beier 1995). In our study, blood meals were offered after a two day interval, a time period that is sufficient for the normalization of enzyme activity. Our observations thus may not have been due to the deleterious effect of midgut proteinases. However the possibility that feeding on multiple blood meals may lead to an abundance of nutrients needed for oocyst development cannot be ignored. For instance, the rapid growth of oocysts on the midgut wall is greatly enhanced by nutrients present in the mosquito hemocoel (Beier and Vanderberg 1998). Moreover, examination of the oocyst loads in blood fed and sugar fed mosquitoes, showed that a higher proportion of the blood fed mosquitoes developed oocysts, further demonstrating that blood meals preceding the infectious blood meal may increase nutritional components in the mosquito that are important for malaria parasite development in the mid gut.

Sugar feeding did not influence oocyst infection rates or infection intensities. Although our data shows that a slightly higher proportion of gametocyte carriers produced infections in mosquitoes not fed sugar, the malaria infection outcome did not differ with that of mosquitoes provided glucose. Sugar may be a facultative requirement for female mosquitoes largely to fill up an energetic shortfall in the absence of blood meals. It has been shown that freshly emerged young mosquitoes are more attracted to sugar than to potential blood sources (Foster and Takken 2004). This appears to be largely a survival strategy for the vulnerable young mosquitoes and may not affect malaria infection rates in vector populations. However the potential impact of sugar sources from wild plants (Impoinvil et al. 2004) on malaria development may be interesting to study as many plants fed on by An. gambiae may have lectins (Jacobson and Schlein 1999, Impoinvil et al. 2004), which can

Table 3. The oocyst infection rates and oocyst intensity listed per individual gametocyte carrier in experiments using mosquitoes of different nutritional histories. Numbers in parenthesis represent proportion of infected mosquitoes per infection experiments.

\begin{tabular}{|c|c|c|c|c|c|c|c|c|}
\hline \multicolumn{2}{|c|}{ Gametocyte } & \multirow[b]{2}{*}{ Macros $\dagger$} & \multicolumn{3}{|c|}{ Oocyst infection rate } & \multicolumn{3}{|c|}{ Oocyst intensity } \\
\hline carrier & Density & & no blood & 1 blood meal & 2 blood meals & no blood & 1 blood meal & 2 blood meals \\
\hline 1 & 160 & 158.4 & $0.0(0 / 6)$ & $0.0(0 / 2)$ & $0.0(0 / 1)$ & 0 & 0 & 0 \\
\hline 2 & 32 & 31.7 & $0.0(0 / 9)$ & $100.0(4 / 4)$ & $100.0(4 / 4)$ & 0 & 1 & 1 \\
\hline 3 & 16 & 15 & $0.0(0 / 14)$ & $4.6(1 / 22)$ & $0.0(0 / 13)$ & 0 & 1 & 0 \\
\hline 4 & 32 & 31 & $18.5(5 / 27)$ & $28.6(2 / 7)$ & $30.8(4 / 13)$ & 1.2 & 2 & 1.8 \\
\hline 5 & 96 & 95 & $0.0(0 / 2)$ & $0.0(0 / 4)$ & $0.0(0 / 2)$ & 0 & 0 & 0 \\
\hline 6 & 336 & 332 & $0.0(0 / 14)$ & $33.3(4 / 12)$ & $50.0(10 / 20)$ & 0 & 1 & 2 \\
\hline 7 & 32 & 31 & $0.0(0 / 20)$ & $0.0(0 / 18)$ & $60.0(12 / 20)$ & 0 & 0 & 1.8 \\
\hline 8 & 16 & 15 & $0.0(0 / 22)$ & $0.0(0 / 12)$ & $0.0(0 / 19)$ & 0 & 0 & 0 \\
\hline 9 & 96 & 95 & $0.0(0 / 6)$ & $6.1(2 / 33)$ & $5.0(1 / 20)$ & 0 & 2 & 1 \\
\hline 10 & 16 & 15 & $0.0(0 / 3)$ & $0.0(0 / 4)$ & $0.0(0 / 2)$ & 0 & 0 & 0 \\
\hline 11 & 16 & 15 & $0.0(0 / 3)$ & $0.0(0 / 3)$ & $0.0(0 / 3)$ & 0 & 0 & 0 \\
\hline 12 & 32 & 31 & $25.0(4 / 16)$ & $16.7(1 / 6)$ & $33.3(3 / 9)$ & 1.3 & 1 & 2.3 \\
\hline 13 & 32 & 31 & $5.6(4 / 72)$ & $0.0(0 / 34)$ & $0.0(0 / 51)$ & 1.3 & 0 & 0 \\
\hline 14 & 16 & 15 & $0.0(0 / 2)$ & $0.0(0 / 2)$ & $0.0(0 / 6)$ & 0 & 0 & 0 \\
\hline 15 & 16 & 15 & $0.0(0 / 1)$ & $0.0(0 / 2)$ & $0.0(0 / 8)$ & 0 & 0 & 0 \\
\hline 16 & 16 & 15 & $0.0(0 / 1)$ & $0.0(0 / 9)$ & $0.0(0 / 10)$ & 0 & 0 & 0 \\
\hline 17 & 16 & 15 & $0.0(0 / 2)$ & $0.0(0 / 2)$ & $0.0(0 / 1)$ & 0 & 0 & 0 \\
\hline 18 & 16 & 15 & $0.0(0 / 7)$ & $0.0(0 / 5)$ & $75.0(3 / 4)$ & 0 & 0 & 1 \\
\hline 19 & 16 & 15 & $33.3(1 / 3)$ & $0.0(0 / 5)$ & $0.0(0 / 12)$ & 1 & 0 & 0 \\
\hline 20 & 16 & 15 & $0.0(0 / 7)$ & $0.0(0 / 9)$ & $0.0(0 / 15)$ & 0 & 0 & 0 \\
\hline 21 & 16 & 15 & $0.0(0 / 30)$ & $0.0(0 / 16)$ & $0.0(0 / 30)$ & 0 & 0 & 0 \\
\hline 22 & 16 & 15 & $100(4 / 4)$ & $0.0(0 / 2)$ & $0.0(0 / 2)$ & 1 & 0 & 0 \\
\hline 23 & 32 & 31 & $0.0(0 / 270$ & $0.0(0 / 22)$ & $0.0(0 / 18)$ & 0 & 0 & 0 \\
\hline 24 & 32 & 31 & $0.0(0 / 1)$ & $0.0(0 / 2)$ & $0.0(0 / 4)$ & 0 & 0 & 0 \\
\hline 25 & 16 & 15 & $0.0(0 / 22)$ & $5.9(1 / 17)$ & $12.5(3 / 24)$ & 0 & 2 & 1 \\
\hline 26 & 272 & 269 & $7.7(1 / 13)$ & $0.0(0 / 17)$ & $0.0(0 / 6)$ & 2 & 0 & 0 \\
\hline 27 & 32 & 31 & $0.0(0 / 1)$ & $0.0(0 / 5)$ & $0.0(0 / 5)$ & 0 & 0 & 0 \\
\hline 28 & 16 & 15 & $10.0(1 / 10)$ & $5.0(1 / 20)$ & $0.0(0 / 9)$ & 1 & 1 & 0 \\
\hline 29 & 16 & 15 & $0.0(0 / 4)$ & $0.0(0 / 3)$ & $0.0(0 / 10)$ & 0 & 0 & 0 \\
\hline & & & ${ }^{*} 5.4(20 / 374)$ & ${ }^{*} 5.7(18 / 318)$ & ${ }^{*} 11.6(40 / 344)$ & ${ }^{\natural} 1.2 \pm 0.1$ & ${ }^{\top} 1.3 \pm 0.2$ & ${ }^{\natural} 1.5 \pm 0.2$ \\
\hline
\end{tabular}

$\dagger$ The mean macrogametocyte density ingested by the mosquitoes was estimated by multiplying the mean blood meal volume of membrane fed mosquitoes by the mean number of macrogametocytes per $\mathrm{ml}$ of blood as described by Okech et al. (2004).

*Represents the overall oocyst infection rates computed by the total number of positive mosquitoes divided by the total number of mosquitoes dissected.

ITThe average of the mean oocyst count on infected mosquito midguts \pm standard error of the mean (SEM). 
Okech BA, Gouagna LC, Kabiru EW, Beier JC, Yan G., and Githure JI. 2004. Influence of age and previous diet of Anopheles gambiae on the infectivity of natural Plasmodium falciparum gametocytes from human volunteers. 8pp. Journal of Insect Science, 4:33, Available online: insectscience.org/4.33

potentially inhibit malaria infection to mosquitoes. Further field studies may shed more light on natural sugar feeding by African malaria vector populations and malaria transmission.

In conclusion, aging may not have any influence on malaria parasite infectivity to An. gambiae. More importantly, this study indicates that behavioral responses associated with foraging for sugars coupled with anthropophagy of An. gambiae mosquitoes may be a boon for the spread of malaria parasites in nature. Factors or mechanisms present in the mosquito blood meal beneficial to malaria oocyst development may warrant further investigations.

\section{Acknowledgements}

Many thanks to Peter Obare and Lucy Owino for the screening and recruitment of human volunteers, Hassan Akello, Jackton Arija, Silas Otieno and Samuel Orao for insectary operations and other ICIPE-Mbita staff members for providing logistical support We acknowledge also Elizabeth Walczak for statistical assistance and Immaculate Okeyo for providing electronic library support. We also greatly appreciate the cooperation for this work received from the local chiefs, clan elders, village communities, schools and head teachers. Also many thanks go to Mbita Health Centre personnel for their support.

This study was supported by NIH grants U19AI45511, D43TWO1143 and D43TW00920. BAO received further support from an ICIPE African Regional Postgraduate Programme in Insect Science (ARPPIS) training fellowship. This paper has been published with the permission of the Director, Kenya Medical Research Institute (KEMRI).

Table 4. The infectivity of Plasmodium falciparum to mosquito groups provided distilled water and $10 \%$ glucose. The parameters used to monitor infectivity are oocyst infection rates and oocyst intensity. The infection experiments are listed as per the gametocyte carriers used in the study.

\begin{tabular}{|c|c|c|c|c|c|c|}
\hline \multicolumn{2}{|c|}{ Gametocytes } & \multirow[b]{2}{*}{ Macros $\dagger$} & \multicolumn{2}{|c|}{ Oocyst infection rate } & \multicolumn{2}{|c|}{ Oocyst intensity } \\
\hline carrier & density & & no sugar & sugar & no sugar & sugar \\
\hline 1 & 80 & 79.2 & $0(0 / 21)$ & $0(0 / 6)$ & 0 & $\overline{0}$ \\
\hline 2 & 2720 & 2692.8 & $0(0 / 13)$ & $0(0 / 20)$ & 0 & 0 \\
\hline 3 & 16 & 15.84 & $0(0 / 42)$ & $0(0 / 27)$ & 0 & 0 \\
\hline 4 & 96 & 95.04 & $0(1 / 11)$ & $5.9(1 / 17)$ & 1 & 1 \\
\hline 5 & 16 & 15.84 & $0(0 / 47)$ & $0(0 / 39)$ & 0 & 0 \\
\hline 6 & 16 & 15.84 & $0(0 / 45)$ & $0(0 / 42)$ & 0 & 0 \\
\hline 7 & 16 & 15.84 & $0(0 / 36)$ & $0(0 / 23)$ & 0 & 0 \\
\hline 8 & 32 & 31.68 & $0(0 / 13)$ & $0(0 / 23)$ & 0 & 0 \\
\hline 9 & 48 & 47.52 & $4.9(2 / 41)$ & $0(0 / 42)$ & 1 & 0 \\
\hline 10 & 96 & 95.04 & $0(0 / 27)$ & $0(0 / 22)$ & 0 & 0 \\
\hline 11 & 144 & 142.56 & $27.0(10 / 37)$ & $38.9(7 / 18)$ & 2.2 & 11.2 \\
\hline 12 & 496 & 491.04 & $6.3(1 / 16)$ & $8.3(2 / 24)$ & 1 & 1 \\
\hline 13 & 32 & 31.68 & $0(0 / 35)$ & $0(0 / 69)$ & 0 & 0 \\
\hline 14 & 80 & 79.2 & $3.3(1 / 30)$ & $5.4(2 / 37)$ & 1 & 1 \\
\hline 15 & 48 & 47.52 & $0(0 / 15)$ & $0(0 / 33)$ & 0 & 0 \\
\hline 16 & 32 & 31.68 & $0(0 / 36)$ & $0(0 / 36)$ & 0 & 0 \\
\hline 17 & 64 & 63.36 & $5.9(1 / 17)$ & $0(0 / 6)$ & 1 & 0 \\
\hline 18 & 48 & 47.52 & $0(0 / 21)$ & $0(0 / 24)$ & 0 & 0 \\
\hline 19 & 16 & 15.84 & $2.4(1 / 42)$ & $0(0 / 45)$ & 1 & 0 \\
\hline \multirow[t]{2}{*}{20} & 16 & 15.84 & $0(0 / 43)$ & $2.6(1 / 39)$ & 0 & 1 \\
\hline & & & $* 2.9(17 / 588)$ & $* 2.2(13 / 592)$ & $\pi_{1.2 \pm 0.2}$ & $\Phi_{3.03 \pm 2.02}$ \\
\hline
\end{tabular}

$\dagger$ The mean macrogametocyte (=macros) density ingested by the mosquitoes was estimated by multiplying the mean blood meal volume of membrane fed mosquitoes by the mean number of macrogametocytes per $\mathrm{ml}$ of blood as described by Okech et al. (2004). *Represents the overall oocyst infection rates computed by the total number of positive mosquitoes divided by the total number of mosquitoes dissected.

ITThe average of the mean oocyst count on infected mosquito midguts \pm standard error of the mean (SEM). 
Okech BA, Gouagna LC, Kabiru EW, Beier JC, Yan G., and Githure JI. 2004. Influence of age and previous diet of Anopheles gambiae on the infectivity of natural Plasmodium falciparum gametocytes from human volunteers. 8pp. Journal of Insect Science, 4:33, Available online: insectscience.org/4.33

\section{References}

Beier JC. 1996. Frequent blood-feeding and restrictive sugar-feeding behavior enhance the malaria vector potential of Anopheles gambiae s.l. and An. funestus (Diptera: Culicidae) in western Kenya. Journal of Medical Entomology 33: 613-618.

Beier JC, Vanderberg JP. 1998. Sporogonic development in the mosquito. In Irwin W. Sherman Editor. Malaria Parasite Biology, Pathogenesis and Protection, 49-61, Washington DC: ASM Press.

Billingsley PF, Hecker H. 1991. Blood digestion in the mosquito, Anopheles stephensi Liston (Diptera: Culicidae): activity and distribution of trypsin, aminopeptidase, and alphaglucosidase in the midgut. Journal of Medical Entomology 28: 865-871.

Briegel H, Horler E. 1993. Multiple blood meals as a reproductive strategy in Anopheles (Diptera: culicidae). Journal of Medical Entomology 30: 975-985.

Chadee DD, Beier JC. 1995. Blood-digestion kinetics of four Anopheles species from Trinidad, West Indies. Annals of Tropical Medicine and Parasitology 89: 531-540.

Clements AN. 1992. Development, Nutrition and Reproduction, The Biology of Mosquitoes. London: Chapman \& Hall.

Ferguson HM, Read AF. 2002. Genetic and environmental determinants of malaria parasite virulence in mosquitoes. Proceedings of the Royal Society of London Biological Sciences 269: 1217-1224.

Foster WA. 1995. Mosquito sugar feeding and reproductive energetics. Annual Review of Entomology 40: 443-474.

Foster WA, Takken W. 2004. Nectar-related vs. human-related volatiles: behavioural response and choice by female and male Anopheles gambiae (Diptera: Culicidae) between emergence and first feeding. Bulletin of Entomological Research 94: 145-157.

Gary RE, Foster WA. 2001. Effects of available sugar on the reproductive fitness and vectorial capacity of the malaria vector Anopheles gambiae (Diptera: Culicidae). Journal of Medical Entomology 38: 22-28.

Gass RF. 1977. Influences of blood digestion on the development of Plasmodium gallinaceum (Brumpt) in the midgut of Aedes aegypti (L.). Acta Tropica 34: 127-140.

Githeko AK. Brandling-Bennett AD, Beier M, Atieli F, Owaga M, Collins FH. 1992. The reservoir of Plasmodium falciparum malaria in a holoendemic area of western Kenya. Transactions of the Royal Society of Tropical Medicine and Hygiene 86: 371-372.

Gouagna LC, Okech BA, Kabiru EW, Killeen GF, Obare P, Ombonya S, Beier JC, Knols BG, Githure JI, Yan G. 2003. Infectivity of Plasmodium falciparum gametocytes in patients attending rural health centres in western Kenya. East African Medical Journal 80: 627-634.

Gouagna LC, Ferguson HM, Okech BA, Killeen GF, Kabiru EW, Beier JC, Githure JI, Yan G. 2004. Plasmodium falciparum malaria disease manifestations in humans and transmission to Anopheles gambiae: a field study in Western Kenya. Parasitology 128: 235-243.

Impoinvil DE, Kongere JO, Foster WA, Njiru BN, Killeen GF, Githure
JI, Beier JC, Hassanali A, Knols BG. 2004. Feeding and survival of the malaria vector Anopheles gambiae on plants growing in Kenya. Medical and Veterinary Entomology 18: 108-1015.

Jacobson RL, Schlein Y. (1999) Lectins and toxins in the plant diet of Phlebotomus papatasi (Diptera: Psychodidae) can kill Leishmania major promastigotes in the sandfly and in culture. Annals of Tropical Medicine and Parasitology 93: 351-356.

Kelly R, Edman JD. 1997. Infection and transmission of Plasmodium gallinaceum (Eucoccidia: Plasmodidae) in Aedes aegypti (Diptera: culicidae): Effect of pre-infection sugar meals and post-infection blood meals. Journal of Vector Ecology 22: $36-42$.

Lyimo EO, Koella JC. 1992. Relationship between body size of adult Anopheles gambiae s.l. and infection with the malaria parasite Plasmodium falciparum. Parasitology 104: 233-237.

Muirhead-Thomson RC. 1954. Factors determining the true reservoir of infection of Plasmodium falciparum and Wuchereria bancrofti in a west African village. Transactions of the Royal Society of Tropical Medicine and Hygiene 48: 208-224.

Mutero CM, Ouma JH, Agak BK, Wanderi JA, Copeland RS. 1998. Malaria prevalence and use of self-protection measures against mosquitoes in Suba District, Kenya. East African Medical Journal 75: 11-15.

Nayar JK, Sauerman DMJ. 1975. The effects of nutrition on survival and fecundity in Florida mosquitoes. 2. The utilization of a blood meal for survival. Journal of Medical Entomology 12: 99-103.

Okech BA, Gouagna LC, Killeen GF, Knols BG, Kabiru EW, Beier JC, Yan G, Githure JI. 2003. Influence of sugar availability and indoor microclimate on survival of Anopheles gambiae (Diptera: Culicidae) under semifield conditions in western Kenya. Journal of Medical Entomology 40: 657-663.

Okech BA, Gouagna LC, Kabiru EW, Walczak E, Beier JC, Yan G, Githure JI. 2004. Resistance of early midgut stages of natural Plasmodium falciparum parasites to high temperatures in experimentally infected Anopheles gambiae (Diptera: Culicidae). Journal of Parasitology 90: 764-768.

Shililu J, Mbogo C, Mutero C, Gunter J, Swalm C, Regens J, Keating J, Yan G, Githure J, Beier J. 2003. Spatial distribution of Anopheles gambiae and Anopheles funestus and malaria transmission in Suba District, western Kenya. Insect Science and Its Applications 23: 187-196.

Straif SC, Beier JC. 1996. Effects of sugar availability on the bloodfeeding behavior of Anopheles gambiae (Diptera:Culicidae). Journal of Medical Entomology 33: 608-612.

Takken W, Klowden MJ, Chambers GM. 1998. Effect of body size on host seeking and blood meal utilization in Anopheles gambiae sensu stricto (Diptera: Culicidae): the disadvantage of being small. Journal of Medical Entomology 35: 639-645.

Tchuinkam T, Mulder B, Dechering K, Stoffels H, Verhave JP, Cot M, Carnevale P, Meuwissen JH, Robert V. 1993. Experimental infections of Anopheles gambiae with Plasmodium falciparum of naturally infected gametocyte carriers in Cameroon: factors influencing the infectivity to mosquitoes. Tropical Medicine and Parasitology 44: 271-276. 
Okech BA, Gouagna LC, Kabiru EW, Beier JC, Yan G., and Githure JI. 2004. Influence of age and previous diet of Anopheles gambiae on the infectivity of natural Plasmodium falciparum gametocytes from human volunteers. 8pp. Journal of Insect Science, 4:33, Available online: insectscience.org/4.33

Vaughan JA, Noden BH, Beier JC. 1994. Prior blood feeding effects on susceptibility of Anopheles gambiae (Diptera: Culicidae) to infection with cultured Plasmodium falciparum (Haemosporida: Plasmodiidae). Journal of Medical Entomology 31: 445-449. 